\title{
Numerical simulations of spreading of the Persian Gulf outflow into the Oman Sea
}

\author{
M. Ezam ${ }^{1}$, A. A. Bidokhti ${ }^{1,2}$, and A. H. Javid ${ }^{1}$ \\ ${ }^{1}$ Faculty of Marine Science and Technology, Science and Research Branch, Islamic Azad University, \\ P.O. Box 14155-775, Tehran, Iran \\ ${ }^{2}$ Institute of Geophysics, University of Tehran, P.O. Box 14155-6466, Tehran, Iran
}

Received: 1 December 2009 - Published in Ocean Sci. Discuss.: 14 December 2009

Revised: 23 September 2010 - Accepted: 24 September 2010 - Published: 11 October 2010

\begin{abstract}
A three dimensional numerical model namely POM (Princeton Ocean Model) and observational data are used to study the Persian Gulf outflow structure and its spreading pathways during 1992. In the model, the monthly wind speed data were taken from ICOADS (International Comprehensive Ocean-Atmosphere Data Set) and the monthly SST (sea surface temperatures) were taken from AVHRR (Advanced Very High Resolution Radiometer) with the addition of monthly net shortwave radiations from NCEP (National Center for Environmental Prediction). The mean monthly precipitation rates from NCEP data and the calculated evaporation rates are used to impose the surface salinity fluxes. At the open boundaries the temperature and salinity were prescribed from the mean monthly climatological values from WOA05 (World Ocean Atlas 2005). Also the four major components of the tide were prescribed at the open boundaries. The results show that the outflow mainly originates from two branches at different depths in the Persian Gulf. The permanent branch exists during the whole year deeper than 40m along the Gulf axis and originates from the inner parts of the Persian Gulf. The other seasonal branch forms in the vicinity of the shallow southern coasts due to high evaporation rates during winter. Near the Strait of Hormuz the two branches join and form the main outflow source water. The results of simulations reveal that during the winter the outflow boundary current mainly detaches from the coast well before Ras Al Hamra Cape, however during summer the outflow seems to follow the coast even after this Cape. This is due to a higher density of the colder outflow that leads to more sinking near the coast in winter. Thus, the outflow moves to a deeper depth of about $500 \mathrm{~m}$ (for which
\end{abstract}

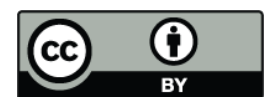

Correspondence to: M. Ezam (ezam@srbiau.ac.ir) some explanations are given) while the main part detaches and spreads at a depth of about $300 \mathrm{~m}$. However in summer it all moves at a depth of about $200-250 \mathrm{~m}$. During winter, the deeper, stronger and wider outflow is more affected by the steep topography, leading to separation from the coast. While during summer, the weaker and shallower outflow is less influenced by bottom topography and so continues along the boundary.

\section{Introduction}

The Persian Gulf is a semi-enclosed marginal sea and is located between $24-30^{\circ} \mathrm{N}$ and $48-56.5^{\circ} \mathrm{E}$. It extends in northwest-southeast direction and is connected to the Indian Ocean through the Strait of Hormuz and the Oman Sea. The high evaporation rate between $1.5-2 \mathrm{~m} \mathrm{yr}^{-1}$ (Chao et al., 1992) and the shallowness of the Persian Gulf especially in the vicinity of the southern coasts lead to formation of saline and dense water with maximum salinity up to about $57 \mathrm{psu}$ in shallow estuaries along the southern coasts (John et al., 1990); although the maximum salinity range over most of the Persian Gulf is about 40.0-40.5 psu (Brewer et al., 1978; Chao et al., 1992). More saline water in the Persian Gulf is observed during the first half of the year compared to the second half (Bower et al., 2000; Johns et al., 2003), and it is colder by several degrees during February-June compared to July-January. The saline water sinks to the deeper zone due to higher density and forms a density front. Then the dense water exits the Persian Gulf through the Strait of Hormuz as a bottom boundary current, banked against southern coasts, and fresher Indian Ocean water enters the Persian Gulf as a surface current mainly on the northern side (Brewer et al., 1978; Chao et al., 1992; Swift and Bower; 2003).

Published by Copernicus Publications on behalf of the European Geosciences Union. 
The dynamics of dense fluids descending on an inclined boundary have been the subject of studies in oceanography. For example Jungclaus and Mellor (2000) investigated the Mediterranean outflow through the Strait of Gibraltar using a three-dimensional numerical model (POM). They concluded that the outflow is controlled by pressure gradient, Coriolis force, entrainment and bottom friction. They speculated that the combined effects of stratification, differential entrainment, and routing by topography lead to the evolution of a two core structure in the bottom layer. The Mediterranean outflow after passing Cape St. Vincent becomes hydro-dynamically unstable and lenses of saline water shed from the core and carry the outflow water characteristics into the Atlantic Ocean.

Pous et al. (2004) revealed short-term variability (about two weeks) of the Persian Gulf Outflow (PGO) by direct measurements using surface-drift buoys, hydrological and ADCP data. They attributed this variability to different mechanisms such as advection of the outflow, meander growth and eddy detachment from the outflow as it spreads into the Oman Sea, and diffusion of thermohaline properties of the outflow into the adjacent water masses. A number of individual hydrographic sections across the Gulf of Oman show that PGO moves along the southern boundary of the Gulf between $200 \mathrm{~m}$ to $400 \mathrm{~m}$ depth (Bower et al., 2000).

Matsuyama et al. (1998) investigated the vertical structure of the current and its time variations using ADCP measurement during December 1993-January 1994 in the Strait of Hormuz. They found that the diurnal tidal currents dominate over the semi-diurnal ones in the Strait of Hormuz. They also showed that for the diurnal tide, a tidal front forms during the spring tide but disappears during neap tide, thus the effective water exchange in the Strait occurs during neap tide. Density front formation depends on the strength of density stratification under the same tidal current, because the vertical mixing due to tidal current is suppressed by the strong density stratification.

Bidokhti and Ezam (2009) considered the vertical structures of the PGO and surrounding waters in the Oman Sea using measurements from the ROPME (Regional Organization for the Protection of the Marine Environment) expedition of 1992 measurements (Reynolds, 1993). They argued that the outflow in the Oman Sea exhibits layered structures and attributed them to double diffusive convection as well as internal wave activities. They used a simple dynamical model based on conservation of potential vorticity and the assumption of geostrophic adjustment, to estimate the average velocity and width of the outflow. They also tested some scenarios about salinity change and its effect on the volume transport and width of the outflow without including entrainment effects. They found (using this dynamical model) values of $0.53 \mathrm{~Sv}$ and $0.42 \mathrm{~Sv}$ for PG outflow volume transport at the entrance to the Oman Sea during Feb. and May 1992 respectively. Johns et al. (2003) also estimated the outflow from the PG using direct ADCP measurements and found it to be $0.15 \pm 0.03 \mathrm{~Sv}$. This was based only on the measurements of one station near the southern coast of the Strait of Hormuz inside the Gulf.

In this paper, first a brief description of the threedimensional numerical model POM is presented. Second, for the simulation of the PGO, the model preparation steps include the modelling domain, data preparations and the initial and boundary conditions. Third, the model simulation results are compared with CTD measurements from the ROMPE expedition in 1992. Finally, some characteristics of the PGO that are revealed from the model simulations such as spreading pathways, dynamical features in the Oman Sea and seasonal variations are presented.

\section{The approach}

\subsection{The numerical model}

The Princeton Ocean Model (e.g. Blumberg and Mellor, 1987; Mellor, 2003) is based on hydrostatic primitive equations with Boussinesq approximation, terrain following coordinate (sigma coordinate) system in the vertical and general orthogonal curvilinear system in the horizontal. The numerical grid employed for the spatial discretization is C-grid as presented by Mesinger and Arakawa (1976). The model uses the mode splitting technique which is the separation of the fast barotropic mode solved with high order explicit finite difference methods with external time step, from the slower baroclinic modes solved implicitly with internal time step. In the numerical solution the external and internal time steps are determined from stability condition (CFL, CourantFriedrichs-Levy). For the external mode (barotropic mode), in the transport equations, the constraint of the time step is:

$\Delta t_{\mathrm{E}} \leq \frac{1}{C_{t}}\left|\frac{1}{\delta x^{2}}+\frac{1}{\delta y^{2}}\right|^{-1 / 2}$

where: $C_{t}=2(g H)^{1 / 2}+U_{\max } ; U_{\max }$ is the maximum expected velocity in the domain (here $1 \mathrm{~m} \mathrm{~s}^{-1}$ ), and $\delta x$ and $\delta y$ are horizontal grid spacings which are about $3.5 \mathrm{~km}$ in this case.

For typical coastal ocean condition, the ratio of internal to external time step is around 30-80 (Mellor, 2003). So we set it to 40 .

The vertical mixing coefficients in the model are calculated by a second order turbulence closure model, namely the Mellor-Yamada level 2.5 model of turbulence that is characterized by two quantities, turbulent kinetic energy and turbulent length scale. The background vertical mixing coefficients for temperature, salinity and momentum are set to $2 \times 10^{-5} \mathrm{~m}^{2} \mathrm{~s}^{-1}$ as the default in POM. However, various studies have shown the sensitivity of the model results to different background vertical mixing coefficients. For example, García Berdeal et al. (2002) investigated the plume structure from Columbia River on the US west coast and showed that 


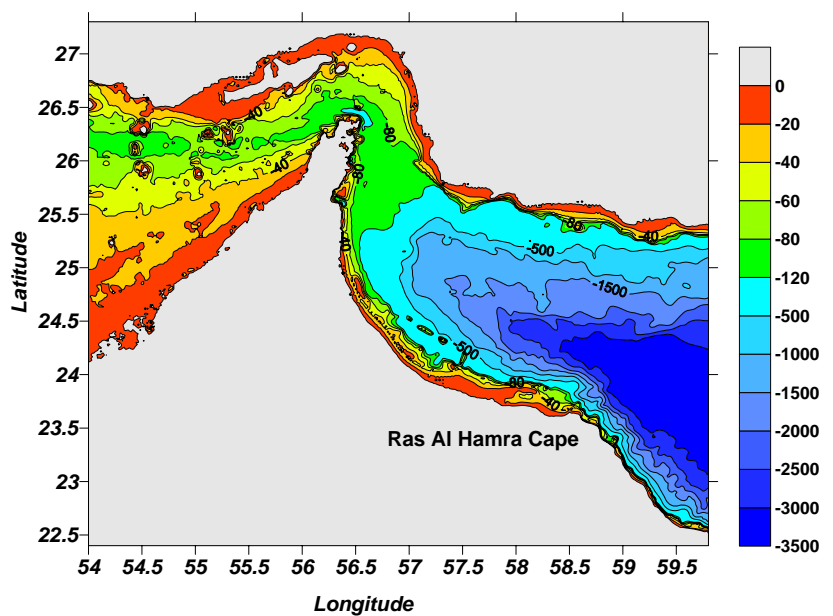

Fig. 1. The modelling domain and topography including east of Persian Gulf and the Oman Sea.

when this background value increases to $10^{-4} \mathrm{~m}^{2} \mathrm{~s}^{-1}$ and especially to $10^{-3} \mathrm{~m}^{2} \mathrm{~s}^{-1}$ the plume spatial structure changes dramatically. In addition, the effect of increasing the vertical mixing coefficient is especially noticeable in the upshelf penetration of the plume and extension of its bulge. They also showed that if the background vertical diffusivity increases to $10^{-4} \mathrm{~m}^{2} \mathrm{~s}^{-1}$ more upstream intrusion is noticeable. Garvine (1999) suggested that, for high Richardson number, holding the constant vertical mixing coefficients at a constant value of $10^{-4} \mathrm{~m}^{2} \mathrm{~s}^{-1}$ and $10^{-3} \mathrm{~m}^{2} \mathrm{~s}^{-1}$ instead of using the closure scheme, yields almost identical results. However, the effects of varying background vertical mixing coefficients are not investigated in this study.

Horizontal diffusions in the model are calculated from the Smogorinsky diffusivity formula as:

$A_{\mathrm{M}}=C \delta x \delta y \frac{1}{2}\left[\left(\frac{\partial u}{\partial x}\right)^{2}+\left(\frac{\partial v}{\partial y}\right)^{2}+\left(\frac{\partial w}{\partial z}\right)^{2}\right]^{1 / 2}$

where $u, v$ and $w$ are velocity components in horizontal and vertical respectively, and $C$ is a non-dimensional parameter and has been recommended to be in range between $0.1-0.2$ (Mellor, 2003). Here it is chosen to be 0.2.

\subsection{The model set up}

The model domain is between $22.4-27.4^{\circ} \mathrm{N}$ and $54-59.8^{\circ} \mathrm{E}$ that includes the eastern part of the Persian Gulf and the Oman Sea as indicated in Fig. 1. The bathymetry of the region was extracted from ETOP02 (Earth Topography 2 arc min), which contains global Earth topography including land with roughly $4 \mathrm{~km}$ resolution, and was interpolated to the grid size of the model. The horizontal grid resolutions are approximately $3.5 \mathrm{~km}$ and we employed 32 vertical layers with non-uniform thickness in order to better represent the surface and bottom boundary layers.

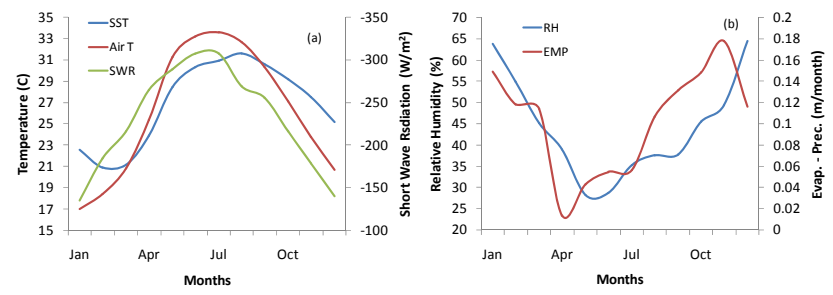

Fig. 2. Domain averaged time series of monthly: (a) Sea Surface Temperature, air temperature and upward short wave radiation, (b) relative humidity and calculated evaporation minus precipitation in 1992.
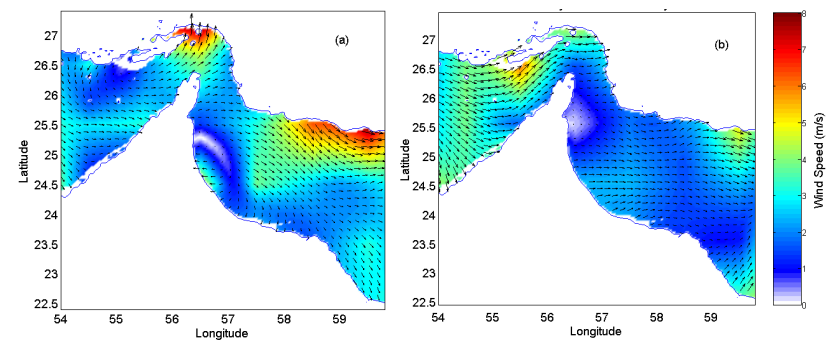

Fig. 3. Typical mean monthly wind fields on the model domain in (a) February and (b) and May 1992.

The climatological annual mean of temperature and salinity was used as initial conditions for temperature and salinity, and was extracted from WOA05 with $0.25^{\circ} \times 0.25^{\circ}$ resolution. The interpolation and extrapolation were performed to map these data on to the model grid in horizontal and vertical directions. The boundary conditions for the model and its setup configurations are given in Appendix A.

In order to calculate the mean monthly evaporation rate at the model grid points according to Eq. (A9), the mean monthly values of air temperature at $2 \mathrm{~m}$ above the sea surface $\left(\sim 1.9^{\circ} \times 1.9^{\circ}\right)$ and mean monthly relative humidity $\left(2.5^{\circ} \times 2.5^{\circ}\right)$ in 1992 , taken from NCEP data, were used.

The domain averaged time series of monthly SST, air temperature and upward short wave radiation are presented in Fig. 2a. In addition, the time series of the calculated monthly evaporation minus precipitation (EMP) and relative humidity are shown in Fig. 2b and typical mean monthly wind fields for Feb and May 1992 are shown in Fig. 3. It is interesting that the minimum value of EMP occurs in April when the surface wind is least.

\section{Results and discussion}

The model was integrated for 10 successive years with monthly varying forcing at the surface and lateral boundaries, until a quasi steady state was reached. The time series of basin averaged kinetic energy and the domain averaged surface salinity for the last 6 years of integrations are shown in 


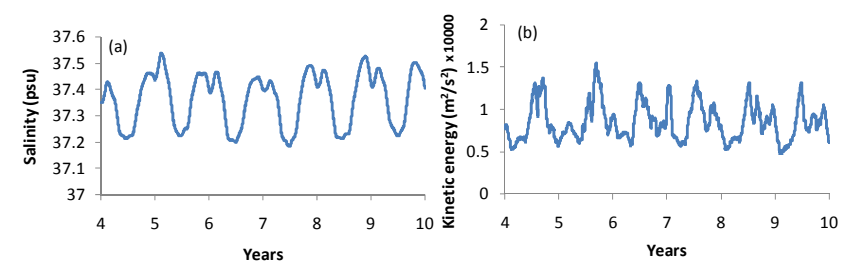

Fig. 4. Domain averaged time series of (a) the surface salinity and (b) the kinetic energy.

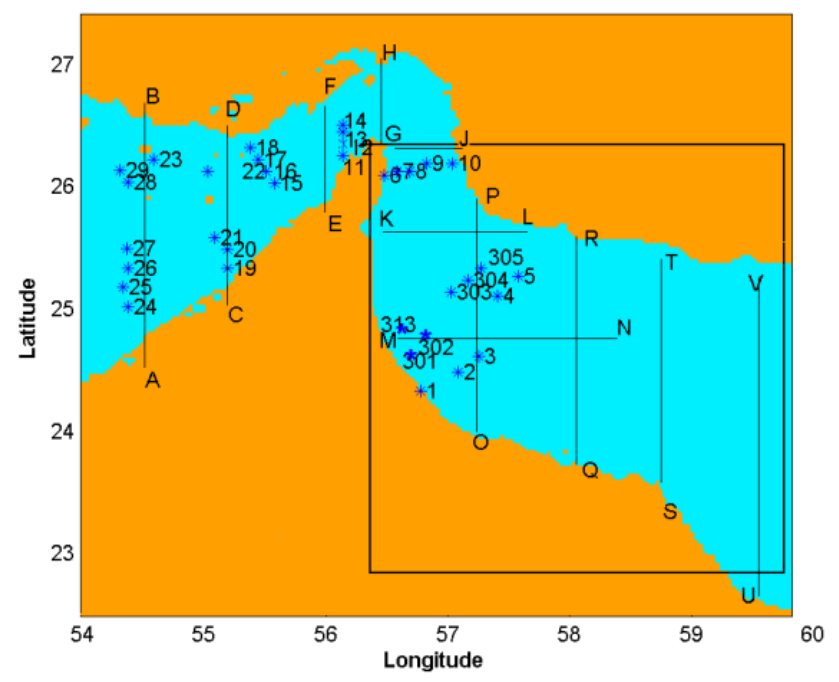

Fig. 5. Location of CTD stations during ROPME expedition (1992). The lines show the cross-sections where model results are extracted.

Fig. 4. All time series have been plotted after taking the moving average of 15 days intervals to filter the tidal and higher frequency changes. In this paper, the results of the last year of integrations are presented.

\subsection{Comparison with observations}

In this section, the model results are compared with some hydrographic measurements of the ROPME expedition in 1992. These data have been collected at two different times of the year and so the temporal variability of the outflow can be considered to some extent. A good review about the ROPME 1992 expedition and the data can be found in Reynolds (1993).

Locations of CTD measurements in the ROPME 1992 expedition during January-February (leg 1) and May-June (leg 6) are shown in Fig. 5. Typical profiles of CTD measurements during legs 1 and 6 for some stations and their almost corresponding points from model simulations are shown in Figs. 6 and 7. Generally, profiles from model simulations show relatively good agreement with observations. But some inconsistencies like the depth of the mixed layer (as seen in the 16 February station) or vertical salinity profile in deeper than $60 \mathrm{~m}$ in the 7 February station are also observed. These
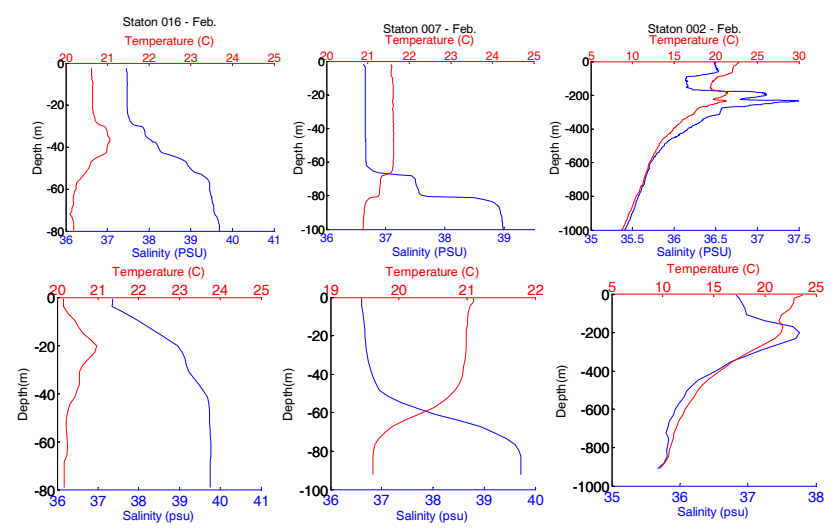

Fig. 6. Typical salinity- temperature profiles during February from CTD measurements (top) and model simualtions (bottom). Locations are shown in Fig. 5.
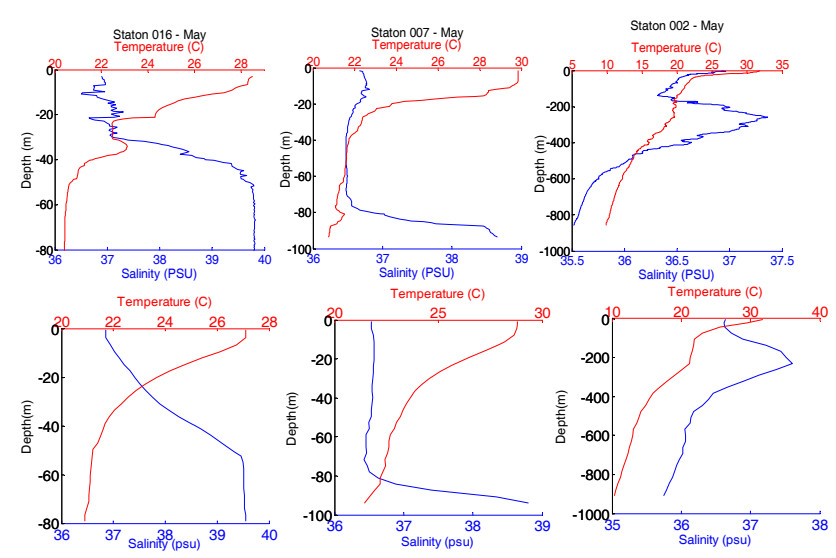

Fig. 7. Typical salinity- temperature profiles during May from CTD measurements (top) and model simualtions (bottom). Locations are shown in Fig. 5.

can be due to the fact that we present monthly mean profiles of model simulations while the CTD measurements are collected in a short period of time so that short time variabilities are included in these measurements due to tidal mixing, instabilities, daily cooling and heating. Also, we have used coarse resolution monthly mean climatological temperature and salinity as representative of inflow characterictics at the open boundaries, and thus the interpolation errors and time varibility must be considered.

\subsection{The outflow characteristics}

In order to investigate the $\mathrm{PGO}$ characteristics at the entrance to the Oman Sea, we focus on the transect IJ (see Fig. 5). Defining the isohaline of the PGO source boundary $\left(S_{\mathrm{O}}\right)$ as an indicator to distinguish it from the surrounding water by:

$S_{\mathrm{O}}=\left(S_{\max }+S_{\text {surr }}\right) / 2$ 

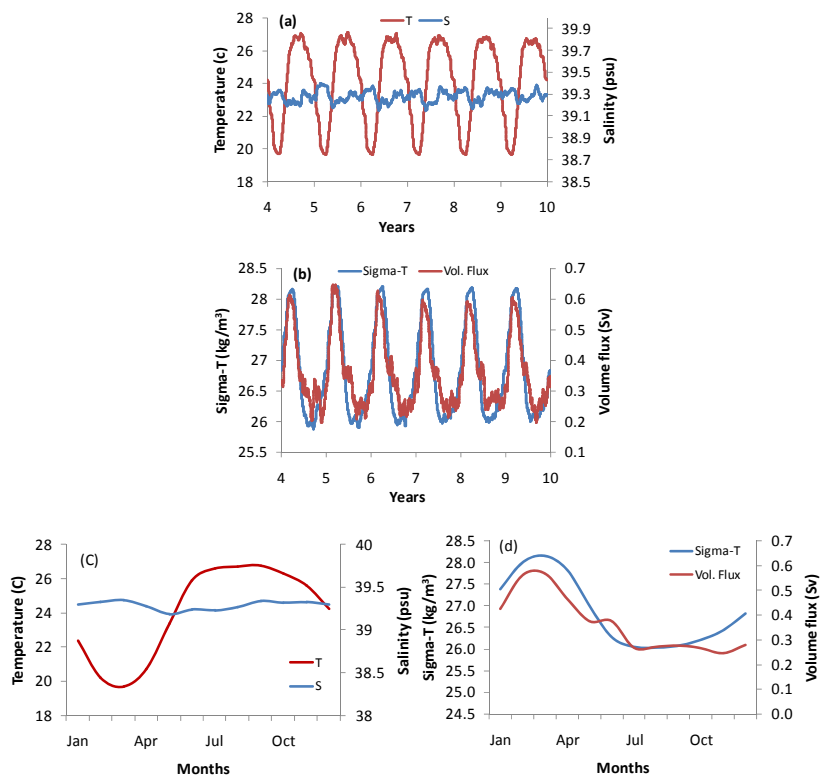

Fig. 8. Time series of (a) the mean PG outflow temperature, salinity, (b) volume flux and $\sigma-T$. (c) The monthly mean for the last year of integrations of the outflow temperature, salinity, (d) volume flux and $\sigma-T$, at transect IJ (see Fig. 4).

where $S_{\max }$ is the maximum of the observed salinity, and $S_{\text {surr }}$ is the area averaged salinity on transect IJ, we can estimate the mean outflow temperature, salinity, $\sigma-T$. The volume transports at this transect are calculated by integrating the southward component of velocities corresponding to the outflow source water. Figure $8 \mathrm{a}$ and $\mathrm{b}$ shows time series of outflow temperature, salinity, $\sigma-T$ and volume transport at transect IJ. The monthly mean values of outflow characteristics were calculated for the last year of integrations as shown in Fig. 8c and d.

The time series show that the PG outflow has an annual variability in temperature between 19.7 and $26.8^{\circ} \mathrm{C}$ in March and August respectively with a mean annual value of about $24^{\circ} \mathrm{C}$. Its salinity is relatively constant and is about $39.3 \mathrm{psu}$ with an annual change of about $0.2 \mathrm{psu}$. The outflow $\sigma-T$ varies between its minimum $\left(26 \mathrm{~kg} \mathrm{~m}^{-3}\right)$ in August to its maximum values $\left(28.2 \mathrm{~kg} \mathrm{~m}^{-3}\right)$ in March with a mean annual of about $26.8 \mathrm{~kg} \mathrm{~m}^{-3}$.

The maximum volume transport of the PG outflow occurs during February-March (about $0.57 \mathrm{~Sv}$ ) and it reaches its minimum value in November (about $0.23 \mathrm{~Sv}$ ) with an annual mean of about $0.35 \mathrm{~Sv}$ at the transect IJ. The simulation results are consistent with finding of Bidokhti and Ezam (2009) but are greater than the estimates of Johns et al. (2003) with an annual mean of $0.2-0.25 \mathrm{~Sv}$ for the PG outflow transport. It may be due to the fact that we estimated the PG volume transport at the entrance to the Oman Sea where dilution could have increased the volume transport. Bower et al. (2000) have estimated the dilution of the Persian Gulf water to the Oman Sea by factor of $\sim 4$.

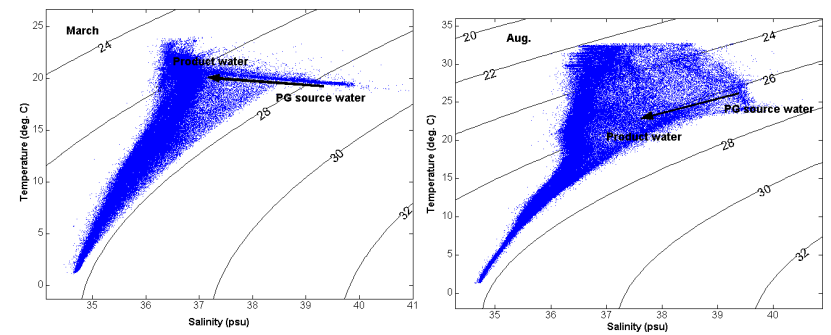

Fig. 9. T-S diagrams of water in the Oman Sea in the box shown in Fig. 5 for March (left) and August (right).

Typical T-S diagrams of the water masses in the Oman Sea for March and August are presented in Fig. 9, indicating that the salinity of the outflow source water is nearly the same for both months (between 39-40 psu). Also the temperature of the outflow source water in March is almost constant and is about $19^{\circ} \mathrm{C}$, but during August, its temperature varies between 22 and $25^{\circ} \mathrm{C}$ (that may be related to the existence of the outflow at different depths along its path). In the Oman Sea, the product waters are indicated by water masses with temperature of about $20^{\circ} \mathrm{C}$ for March and a little higher temperature of about $22^{\circ} \mathrm{C}$ for August. The salinity of product water however, is nearly the same and is about 37.5 psu for both months. Accordingly, the mean $\sigma-T$ of product water is about 26.5 and $26 \mathrm{~kg} \mathrm{~m}^{-3}$ in March and August respectively.

It is also clear that the outflow temperature increases a little from its source in the Persian Gulf to its equilibrated position in the Oman Sea during March, while the temperature reductions of about $4{ }^{\circ} \mathrm{C}$ is observed in outflow during $\mathrm{Au}$ gust.

\subsection{The outflow spreading pathway}

Here, the outflow spreading pathways is investigated at some cross-sections from the inner Persian Gulf to the Oman Sea where it reaches its equilibrium depth during March and August, which are the months when the outflow has its maximum and minimum initial densities (see Fig. 8d). Then horizontal fields are presented to show the spreading pathways. All transects and horizontal fields are plotted after averaging every month to filter the tidal and high frequency changes.

The transects of temperature and salinity in the Persian Gulf (transect CD, Fig. 10) show during March that the temperature is nearly constant and varies from $19-20^{\circ} \mathrm{C}$ from the bottom to the surface. The salinity reaches more than 40 psu near the southern boundary and shows the main position of the high salinity outflow source water. In August, the temperature at the surface seems to be nearly constant at about $33^{\circ} \mathrm{C}$ and it reaches about $22^{\circ} \mathrm{C}$ at the outflow source indicated by the highest salinity below $40 \mathrm{~m}$. The water mass below 37.5 psu is observed on the right side of the transect (in the vicinity of Iranian coast) which shows intrusion of the low salinity waters from the Indian Ocean during August. 

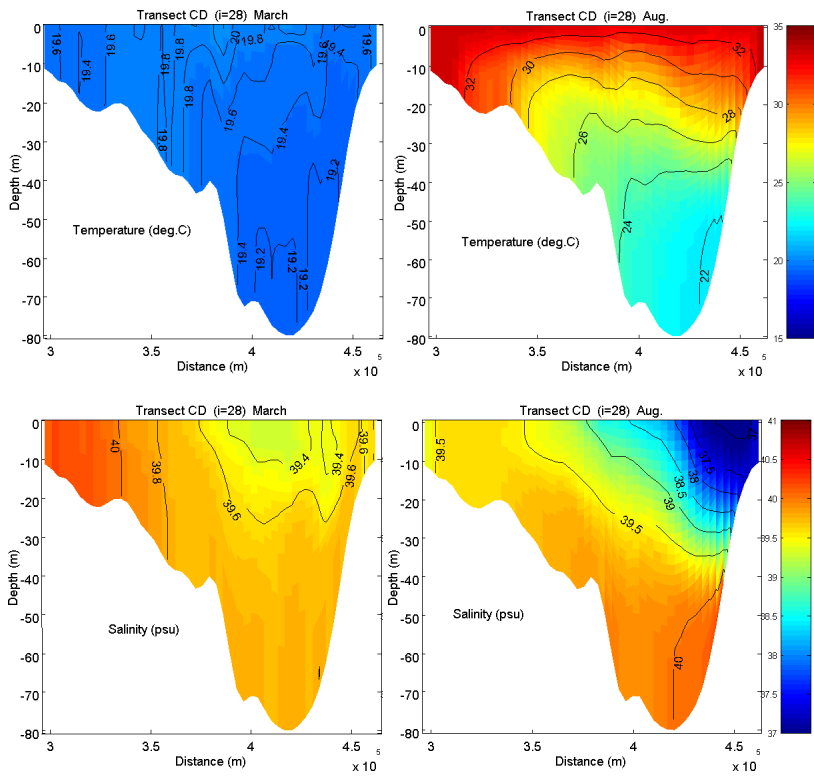

Fig. 10. Cross-section of the mean temperature and salinity along CD path, shown in Fig. 5 obtained from model simulation during March (left) and August (right).

Generally, the simulations indicate that the PGO originates from two branches; one permanent branch exists during almost the whole year in deeper than $40 \mathrm{~m}$ and may form from inner parts of the Persian Gulf. A seasonal branch which forms in the winter months originates from the shallow southern parts. The seasonal branch due to its higher density relative to surrounding water sinks to the deeper zone and joins the permanent branch. Finally, these two branches form the PGO in the bottom of the Gulf in the southern deep part of the Strait of Hormuz (transect IJ). This may have some implications for the outflow depth in the Oman Sea (see below).

Figure 11 shows the monthly mean temperature, salinity and $\sigma-T$ along transects IJ in March and August. In March, the temperature shows a nearly homogenous structure as before in transect $\mathrm{CD}$, and the source of the outflow is indicated by the water mass with salinity above $\sim 39$ psu and a temperature of $\sim 19.5^{\circ} \mathrm{C}$. In August, the vertical temperature differences up to $10^{\circ} \mathrm{C}$ are observed, with a strong thermocline near the surface. The outflow is indicated by salinity above $\sim 39 \mathrm{psu}$, while its temperature varies between 24 and $26^{\circ} \mathrm{C}$. Hence, the mean outflow $\sigma-T$ varies from about $28.1 \mathrm{~kg} \mathrm{~m}^{-3}$ during March to about $26 \mathrm{~kg} \mathrm{~m}^{-3}$ during August, which mainly results from outflow temperature variations of more than about $6^{\circ} \mathrm{C}$.

In the eastern half of the transects, salinities are nearly the same from the surface down to the depth of $60 \mathrm{~m}$ for both months and are about 36.5 psu. But, in the western half of the transects, salinity is higher in August, especially above the depth of $40 \mathrm{~m}$. This may be due to the advection of saline
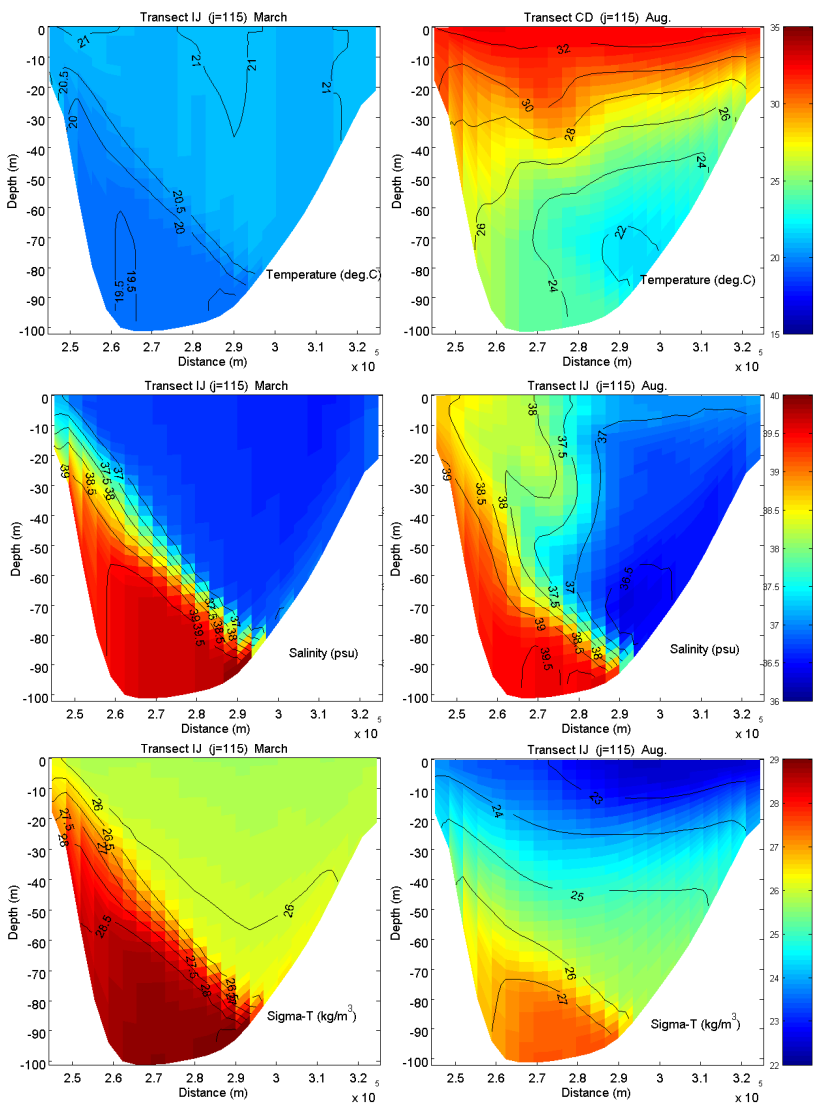

Fig. 11. Cross-section of the mean temperature, salinity and $\sigma$ $T$ along IJ path, shown in Fig. 5 obtained from model simulation during March (left) and August (right).

water by eddies and also to the lower density stratification during August that lead to higher mixing with surrounding waters. As shown in $\sigma-T$ transects, during March (winter months) a two layer density regime is observed, namely an upper layer with $\sigma-T$ of about $26 \mathrm{~kg} \mathrm{~m}^{-3}$ and a lower layer with $\sigma-T$ values larger than $28.5 \mathrm{~kg} \mathrm{~m}^{-3}$. In these transects, pycnostads (characteristic of strong baroclinic ocean currents) are observed.

During August, (summer) a three layer stratification is observed, namely an upper low density layer with $\sigma-T$ of about $23 \mathrm{~kg} \mathrm{~m}^{-3}$, an intermediate layer with about $25.5 \mathrm{~kg} \mathrm{~m}^{-3}$ and a lower layer with about $27 \mathrm{~kg} \mathrm{~m}^{-3}$. It can be concluded from these values that during March higher density differences between benthic layer and upper layer (about $2.5 \mathrm{~kg} \mathrm{~m}^{-3}$ ) leads to higher stratification. Therefore the entrainment and mixing between the outflow and upper layer decreases in comparison with August when the density difference is weaker in the water column (about $1.5 \mathrm{~kg} \mathrm{~m}^{-3}$ ).

The denser and thicker outflow in March (winter) leads to higher outflow velocity and volume transport in contrast to August (summer). The monthly mean velocity components along transect IJ (Fig. 12) exhibit the highest velocities at 

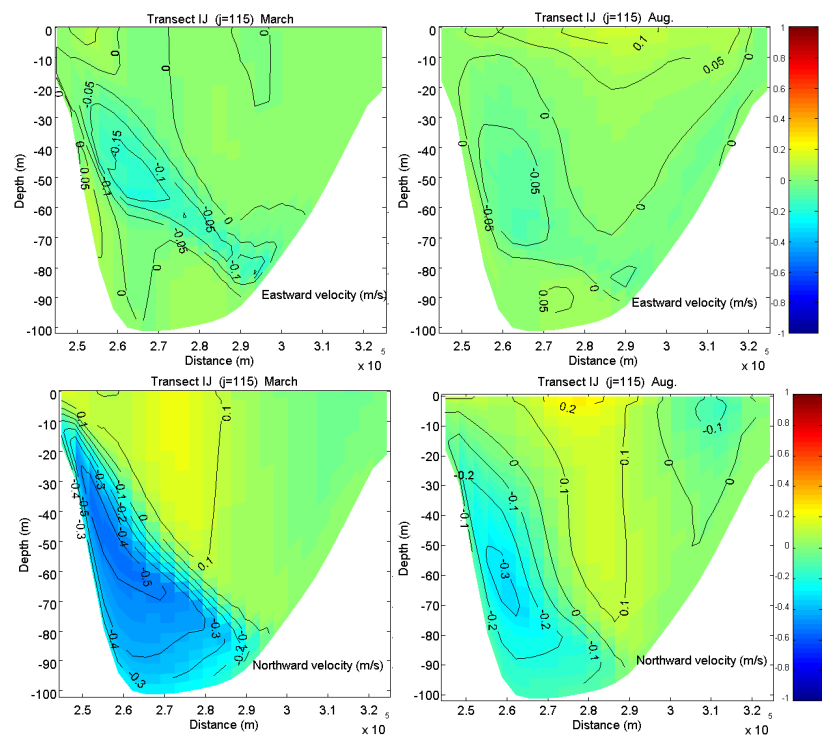

Fig. 12. Cross-section of the mean velocity components along the IJ path shown in Fig. 5, obtained from model simulation during March (left) and August (right).

depths of $30-70 \mathrm{~m}$ with more than $0.5 \mathrm{~ms}^{-1}$ in March, and at depths of $50-70 \mathrm{~m}$ with a velocity of about $0.3 \mathrm{~ms}^{-1}$ in August. The direction of the outflow at these depths is mainly southward. This may make the outflow supercritical (Froude number larger than 1) only for winter as it enters the Oman Sea. The westward component of the flow can be due to thermal wind effects that cause the flow to turn right with height in the Northern Hemisphere.

The $T$ and $S$ characteristics of the outflow along transect $\mathrm{MN}$ are shown in Fig. 13. The main outflow branch is identified in salinity and temperature transects, as saltier and warmer water mass relative to the surrounding water, banks against western coast. In addition, patches with higher salinity and warmer water are also observed that can be the result of instability of the outflow plume and eddy activities. Here, the outflow salinity is nearly the same for both months $\sim 38 \mathrm{psu}$, but its temperature is about $20^{\circ} \mathrm{C}$ and $24^{\circ} \mathrm{C}$ for March and August respectively. It indicates an increase (small decrease) of outflow temperature from its source in the Persian Gulf to the Oman Sea where it reaches the equilibrium depth during March (August).

The denser outflow source water in March, and also lesser entrainment and mixing in comparison with August, lead to outflow intrusion at larger equilibrium depths. Thus, the equilibrated outflow is observed with mean depths of about $200 \mathrm{~m}$ and $500 \mathrm{~m}$ during August and March respectively. The $\sigma-T$ transects (not shown) also confirm that the outflow has reached its equilibrium levels. Figure 9 of Bidokhti and Ezam (2009) based on measurements of ROMPE 1992 also shows that the outflow higher density extends well into deeper part of the Oman Sea in winter in comparison with that of summer (for further discussion see below).
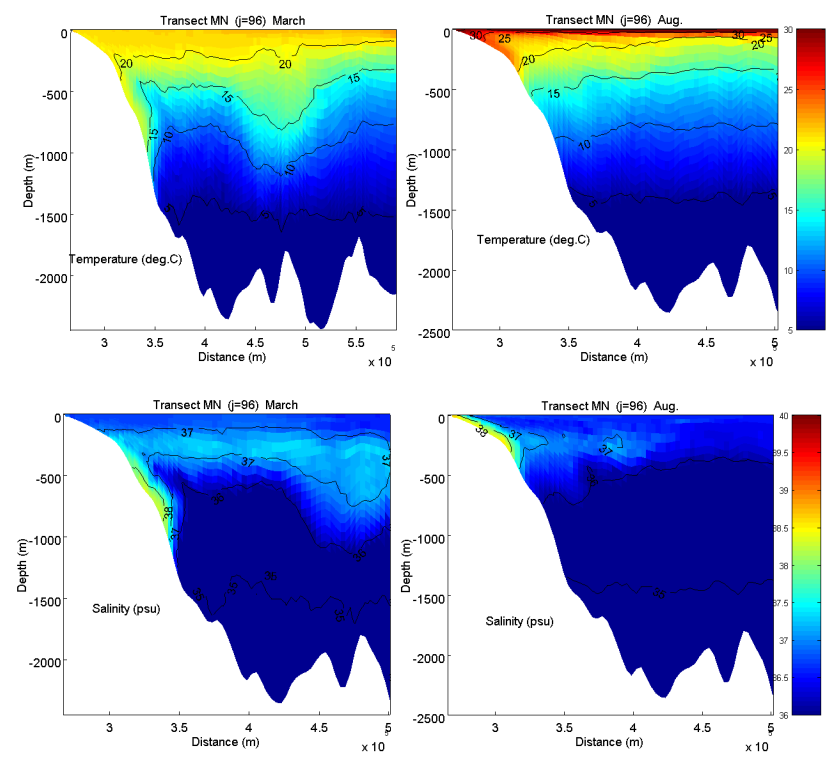

Fig. 13. Cross-section of the mean temperature and salinity along the MN path, shown in Fig. 5 obtained from model simulation during March (left) and August (right).

The horizontal sections of salinity with overlaid velocity field at depth of $10 \mathrm{~m}$ are shown in Fig. 14 for March and August. The figure shows the saltier Persian Gulf water during March in the southern part of the Gulf sinks at the Strait of Hormuz and is not observed at the depth of $10 \mathrm{~m}$ after the Strait. While in August at least part of the outflow moves along the coast of the Oman that indicates it is less dense than that of March period.

In the Oman Sea in March, a dominant cyclonic eddy is observed between $57.5-58.5^{\circ} \mathrm{E}$ and $24-25^{\circ} \mathrm{N}$ with mean velocity of about $0.3 \mathrm{~ms}^{-1}$. Interestingly, in August nearly at the same place $\left(58-59^{\circ} \mathrm{E}\right.$ and $\left.24-25^{\circ} \mathrm{N}\right)$, the dominant eddy is an anti-cyclonic one with mean velocity of about $0.32 \mathrm{~ms}^{-1}$. It appears that the near surface eddy might be generated by the outflow in winter in which it intrudes deeper and the surface winds in Oman Sea are weaker, while in summer the outflow is not as deep and the surface winds in Monsoon time is stronger which may create the anti-cyclonic eddy.

The extended view of the outflow properties including temperature, salinity with overlaid velocity field in the Strait of Hormuz at depth $80 \mathrm{~m}$ are shown in Fig. 15. It shows that the combinations of the colder and saltier outflow source water during March causes the dense outflow to fall down the continental slope and so disappear from upper layers near about $25^{\circ} \mathrm{N}$. In contrast, during August, though the outflow salinity is similar to that in March, its temperature increases more than $6^{\circ} \mathrm{C}$. This leads to a decrease in outflow density by more than $2 \mathrm{~kg} \mathrm{~m}^{-3}$. In addition, the temperature of the outflow varies between 24 and $26^{\circ} \mathrm{C}$. The part having lower temperature sinks down to the greater depth and the warmer 

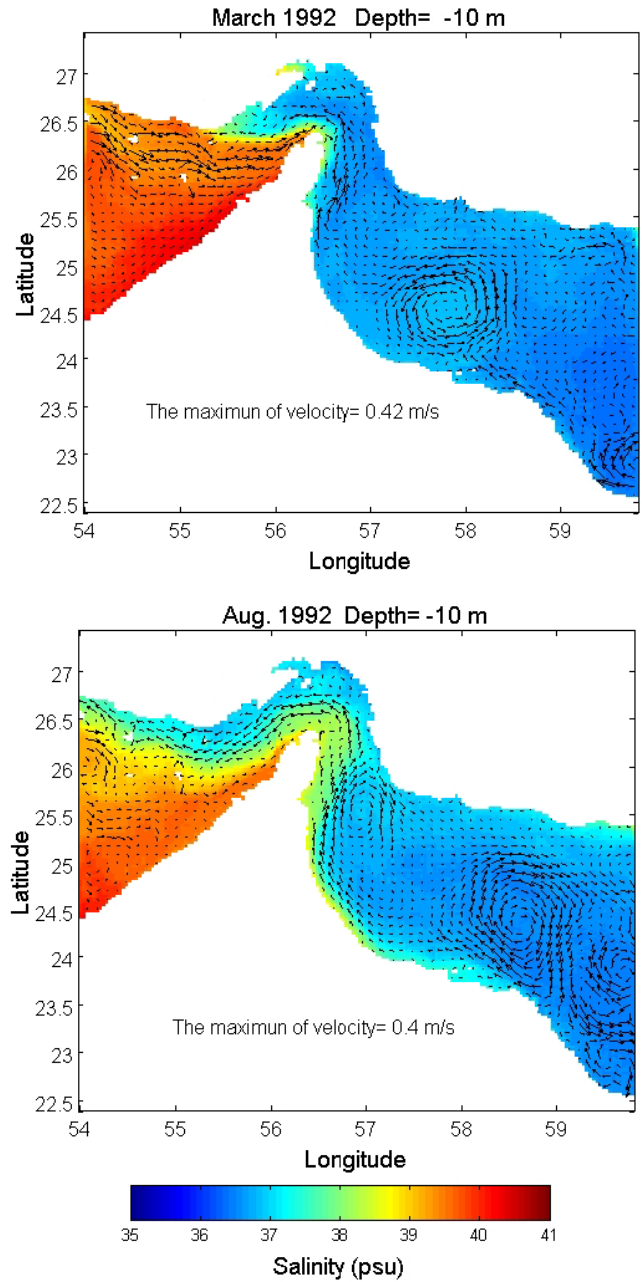

Fig. 14. The mean monthly of horizontal salinity and velocity fields at depth $10 \mathrm{~m}$ for March (up) and August (down).

part finds its equilibrium depth and spreads in the vicinity of the coastal boundaries at shallower depths (see Fig. 15). It seems interesting that the dominant circulation in the Oman Sea in August becomes cyclonic at this depth (Fig. 15), while the surface cyclonic eddy observed in winter still exists at $80 \mathrm{~m}$. Hence the outflow at the depth of $80 \mathrm{~m}$ appears to control the circulations in both seasons at this depth.

The maximum outflow velocities occur where the bottom slope suddenly increases. These velocities are $0.69 \mathrm{~ms}^{-1}$ and $0.35 \mathrm{~ms}^{-1}$ for March and August respectively and are nearly consistent with Bower et al. (2000), who showed the outflow reaches its maximum speed in winter $\left(0.55 \mathrm{~ms}^{-1}\right)$ and its minimum in summer $\left(0.4 \mathrm{~ms}^{-1}\right)$.

Figures 16 and 17 show the horizontal fields of the temperature, salinity and the overlaid velocities at depths $200 \mathrm{~m}$ and $500 \mathrm{~m}$, which are related to the equilibrium depths of the outflow during August and March respectively. The lower source density of the outflow during August causes the appearance of the outflow in the shallower zone relative to that
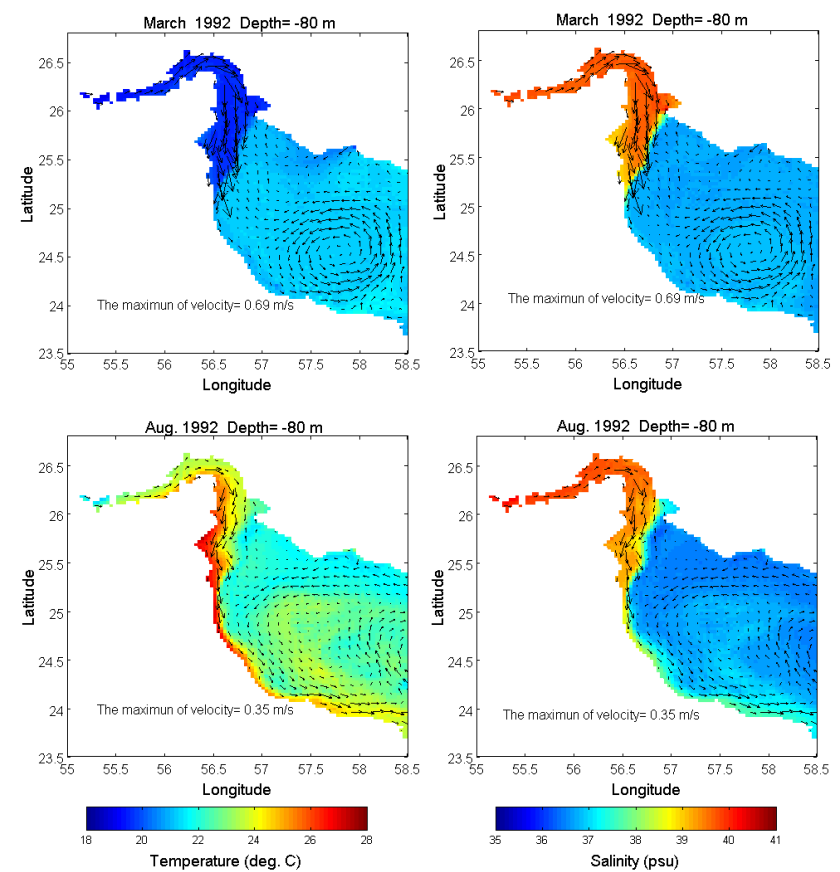

Fig. 15. Horizontal mean fields of temperature (left) and salinity (right) in extended view of the Strait of Hormuz and Oman Sea at depth $80 \mathrm{~m}$ during March and August.
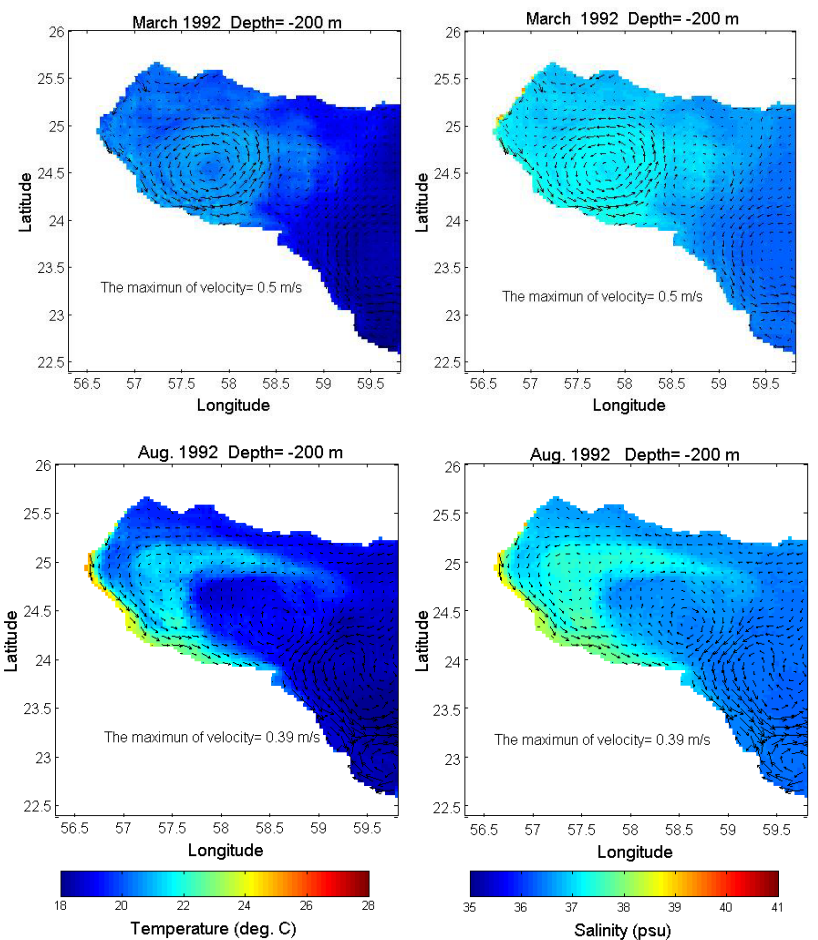

Fig. 16. Horizontal mean fields of temperature and salinity at depth $200 \mathrm{~m}$ for March and August. 

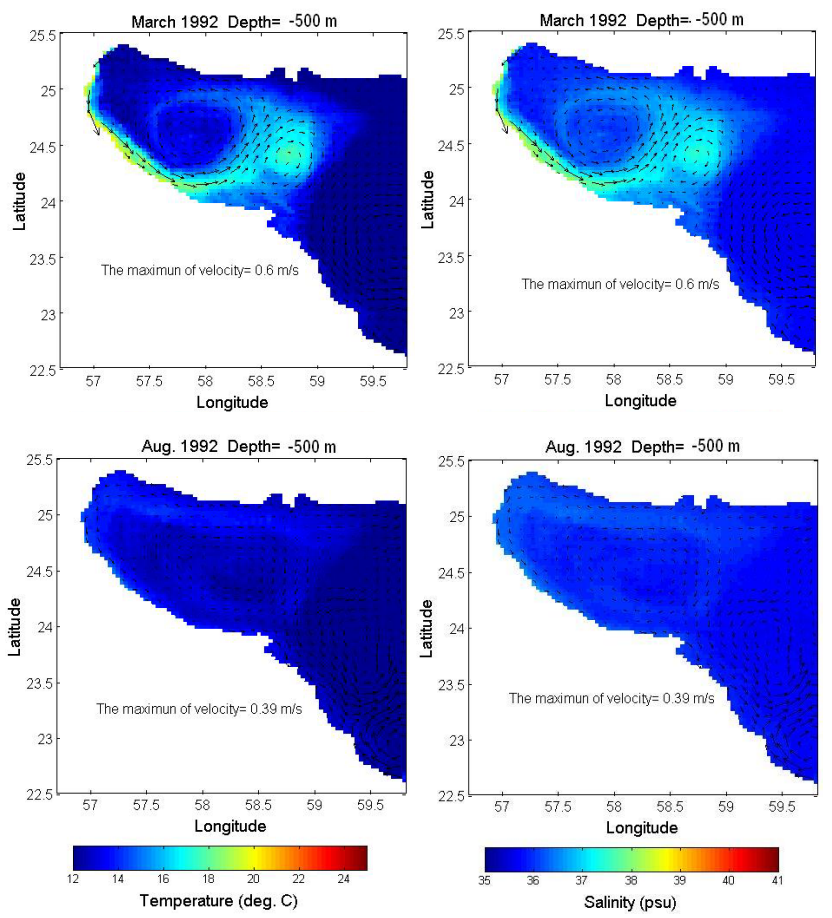

Fig. 17. Horizontal mean fields of temperature and salinity at depth $500 \mathrm{~m}$ for March and August.

of March. Hence, in August the outflow is more evident at the depth of $200 \mathrm{~m}$ and propagates as a narrow boundary current in vicinity of southern and western coasts, disappearing downstream of the the Ras Al Hamra Cape (located at $58.5^{\circ} \mathrm{E}$ and $23.8^{\circ} \mathrm{N}$ ).

As a whole, it could be concluded that during August, the low outflow density and volume flux only create a weak circulation at the depth of the outflow with no substantial effects in the deeper parts. However in March the outflow effect is observed deeper with a marked cyclonic eddy (also seen up to the surface) that appears to be generated by the outflow as it detaches from the bottom of the southern border and spreads into the central part of the Oman Sea. This eddy as well as a smaller anti-cyclonic one are formed further east (Fig. 17) at the depth of the outflow in winter (about 500m). The smaller anti-cyclonic eddy (Peddy, Persian Gulf eddy) contains more outflow characteristics. Senjyu el al. (1998) used field measurements of January 1994 to study the Peddy formation and suggested that it is related to the intermittency of outflow movement through the Strait of Hormuz. They found the depth of the eddy is in the range of $250-400 \mathrm{~m}$ (see Fig. 18).

Several other eddy generation mechanisms have been presented in the literature. For example d'Asaro (1988) suggested that a coastal trapped boundary current may gain anticyclonic vorticity as a result of viscous stress in the boundary layer when it arrives at a cape or canyon. D'Asaro used this theory to explain the permanent existence of an anticyclone
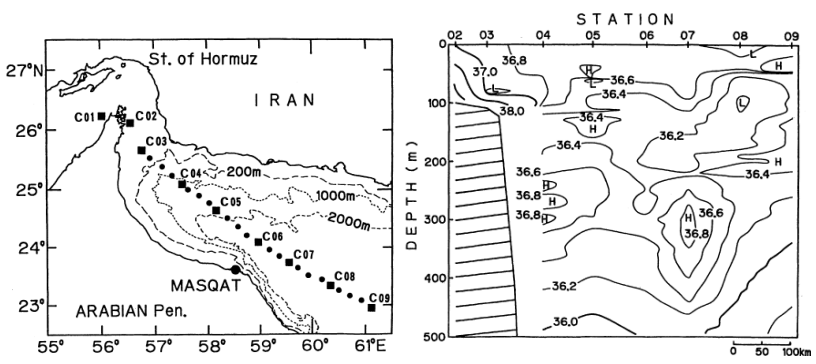

Fig. 18. Locations of CTD measurements during January 1994 (Senjyu et al., 1998) and the corresponding salinity transect.

in the Arctic Ocean. He also speculated that Mediterranean eddies (Meddies) could be generated by the same mechanism as the Mediterranean outflow separates from the continental slope. Bower et al. (1997) from numerous Lagrangian observations and implementation of the d'Asaro model explained the production of Meddies at Cape St. Vincent.

Jungclaus (1999) investigated the evolution of buoyancy driven intermediate flow along an idealized continental slope using a three-dimensional numerical ocean model (POM). He showed that the intruding outflow interacts with overlaying water and vortex compression and stretching takes place. He speculated that the lateral intrusion of the plume into the ambient water column compresses the water above and below and thus anti-cyclonic vorticity is introduced in order to conserve the potential vorticity.

We also performed the simulation without including the tide. The results show that separation of the outflow from lateral boundary occurs as before. But the outflow spreads as an "S" shape meander, and the mentioned Peddy may not form (however, in the absence of tide the salinity and temperature of the outflow change a little because of less mixing induced by tide especially in the Strait of Hormuz). Hence, these results agree more with Senjyu et al. (1998).

Stern (1980) showed that for a coastal gravity current with zero potential vorticity assumption, if the current width far upstream of the nose is less than a critical fraction (0.42) of the Rossby radius of deformation (based on the current depth far upstream), then the nose of the current will propagate along the coast as a bore and the form of the nose may be steady if the friction is able to dissipate sufficient kinetic energy. If the upstream current is wider than this critical value the flow may be blocked and deflected perpendicular to the coast causing separation.

We implemented the Stern theory (however the outflow vorticity may not be zero) to study the behaviour of the outflow near the Ras al Hamra Cape. Extracting the outflow characteristics at a place before the Cape yields: $h \sim$ $500,200 \mathrm{~m}$ (outflow depth); $g^{\prime} \sim 0.015,0.012 \mathrm{~ms}^{-2}$ (reduced gravity), $w \sim 40,10 \mathrm{~km}$ (outflow width) and $f \sim$ $6.0 \times 10^{-5} \mathrm{~s}^{-1}$ (Coriolis parameter) for March and August respectively. Therefore, the corresponding Rossby radius of 

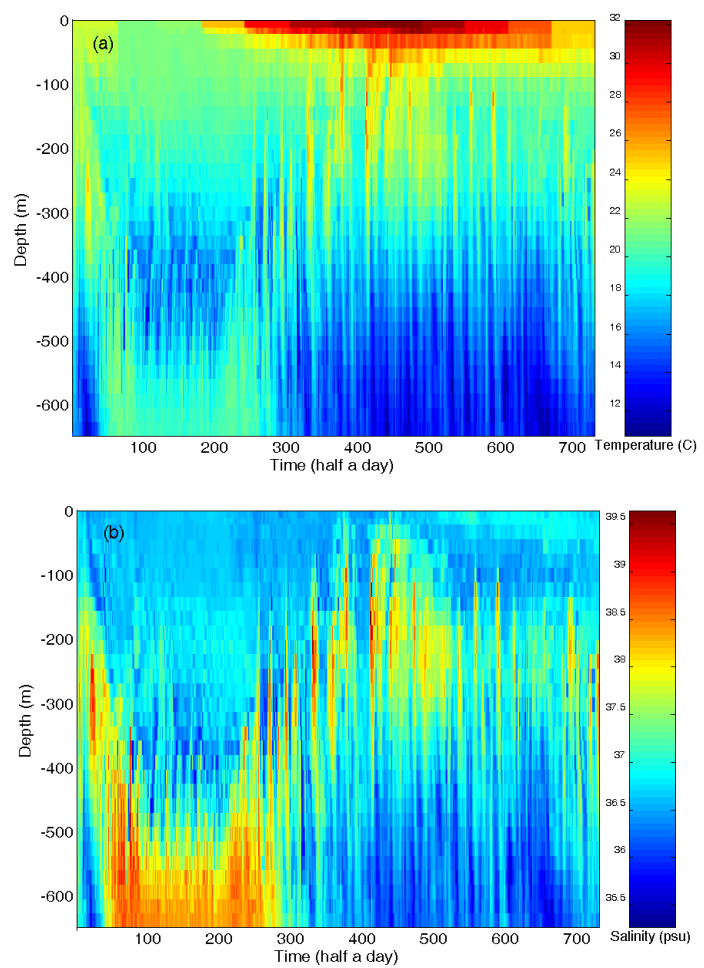

Fig. 19. Time-depth rate of changes of temperature (a) and salinity (b), at a station off the coast of the Oman Sea located at $57^{\circ} \mathrm{E}$ and $24.7^{\circ} \mathrm{N}$. The horizontal axis is scaled from January to December.

deformation $\left(\sqrt{g^{\prime} h} / f\right)$, are approximately equal to 46 and $24 \mathrm{~km}$ for March and August respectively, that lead to critical current widths of order of $19 \mathrm{~km}$ for March and $11 \mathrm{~km}$ for August. Comparing these values with outflow widths, it could be concluded that during March the outflow should detach from the coast and propagate normal to the coast, while during August it could continue its propagation along the coastal boundary (as seen in Figs. 16 and 17).

An additional explanation for the separation and Peddy formation is that during March, as the PG outflow moves to deeper zone of the Oman Sea, encountering the steep topography near the Ras al Hamra Cape (as seen in Fig. 1), the outflow thickness increases (due to stretching processes) and so the compression of water column above and below it take places. Therefore, due to conservation of the potential vorticity an anti-cyclonic circulation may be introduced (as speculated by Jungclaus, 1999).

The time-depth rate of changes in temperature and salinity for the last integration year at a station off the Oman Coast at $\left(57^{\circ} \mathrm{E}\right.$ and $\left.24.7^{\circ} \mathrm{N}\right)$ near the path of the outflow are shown in Fig. 19. It is interesting that the mean depth of the outflow is at about $200-300 \mathrm{~m}$ in the second half of spring, summer and autumn, but as winter begins it sinks to a depth of 400$600 \mathrm{~m}$ until late April and after which it moves to upper depth again. This winter sinking of the outflow appears to be due
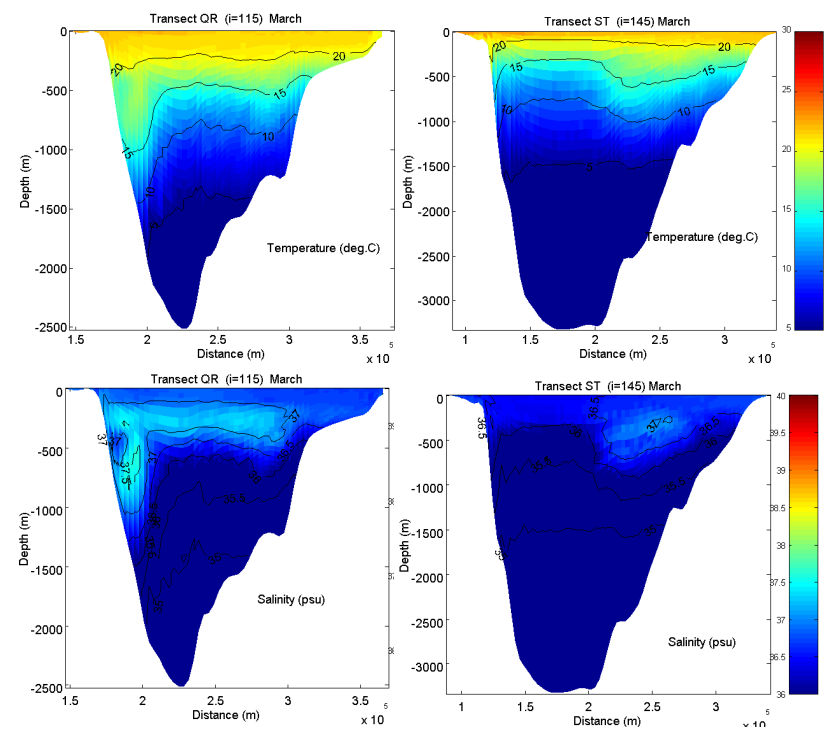

Fig. 20. The mean monthly temperature and salinity along $Q R$ and ST cross sections (see Fig. 5) in March.

to colder temperature of the outflow source water and has not been observed by field studies which are very rare for this area. In some previous literatures (e.g. Senjyu et al., 1998; Bower et al., 2000; Pous et al., 2004) the mean depth of the outflow spreading in the Oman Sea has been found to be at about $250-400 \mathrm{~m}$. The results of this simulation are more or less consistent with the measurements of Senjyu et al. (1998) (Fig. 18), which have been made during January 1994, and the measurements of the Pous et al. (2004), during October and early November 1999. However, more direct measurements are required to verify deeper outflow in late winter in the southern part of the Oman Sea.

The cross sections of $T$ and $S$ further downstream of the outflow in March (see Fig. 5, QR and ST sections) that are shown in Fig. 20 indicate that the outflow mainly spreads at the depth of about $300 \mathrm{~m}$, with a smaller portion near the southern coast of the Oman Sea to deeper parts in winter. It appears that a part of the outflow near the southern coast detaches and sinks near this steep bottom slope. This is not observed further downstream (see cross section ST). Based on the available observations there appears to be some inconsistency between the predicted and observed part of the outflow depth in winter time. A few explanations of this can be made. One is that the POM uses sigma coordinates that may not work properly near steep topography with limited vertical resolutions (32 levels is used here) in this deeper parts. Another is that at the western boundary of the model domain we have used coarse resolution WOA05 data which may have not been realistic for winter time. In addition processes such as double diffusion are rather strong around the outflow boundary (Bidokhti and Ezam, 2009) that may influence the vertical diffusivity that is not considered in the 


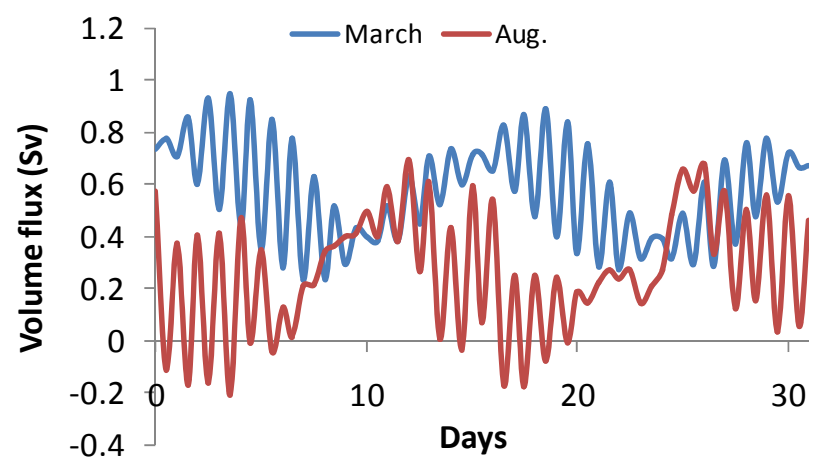

Fig. 21. The short-time variations of the outflow transports during March and August. The data are plotted in half day intervals.

model. Another factor is that some down-welling process in winter may at least sink part of the outflow near the southern boundary as Spall (2008) has shown that such process may results from surface buoyancy loss. Or as the denser outflow in winter can be supercritical just as it enters the Oman Sea, this leads to deepening of its initial path (Afanasyev and Peltier, 2001). In winter, we also showed above that the source water from the PG has an extra branch (cold and salty one along the southern coast, Fig. 10) just before exiting the PG and this could enhance the density of the outflow compared to that of other times when there is mainly the axial deeper branch. Therefore there are a variety of effects that may lead to this winter deepening of part of the outflow near the Oman coast in its initial stage that are required to be further investigated.

\subsection{Effects of tide}

In this section, the interactions of the PGO and the tidal front in the Strait of Hormuz are investigated. This interaction causes the intermittency of the outflow into the Oman Sea. We compare the short time variations of the outflow volume fluxes during March and August at the transect IJ, which are related to the maximum and minimum vertical stratifications respectively. The time series of the outflow discharges during March and August are shown in Fig. 21, which are plotted in half day intervals. The series show that in March, the discharges of the outflow oscillates between $0.9 \mathrm{~Sv}$ and $0.23 \mathrm{~Sv}$ during the tidal cycle, while these values are between about $0.69 \mathrm{~Sv}$ and $-0.15 \mathrm{~Sv}$ for Aug (only based on the flow of source water with salinity defined by Eq. (13)). These values suggested that during March the outflow is always moving into the Oman Sea, however, its transport varies due to interaction with tide. But during August, in addition to the decrease in the maximum discharge of the outflow due to variations in source water characteristics, it seems that there are occasions when the movement of the outflow to the Oman Sea is suspended or somehow reversed by tide.
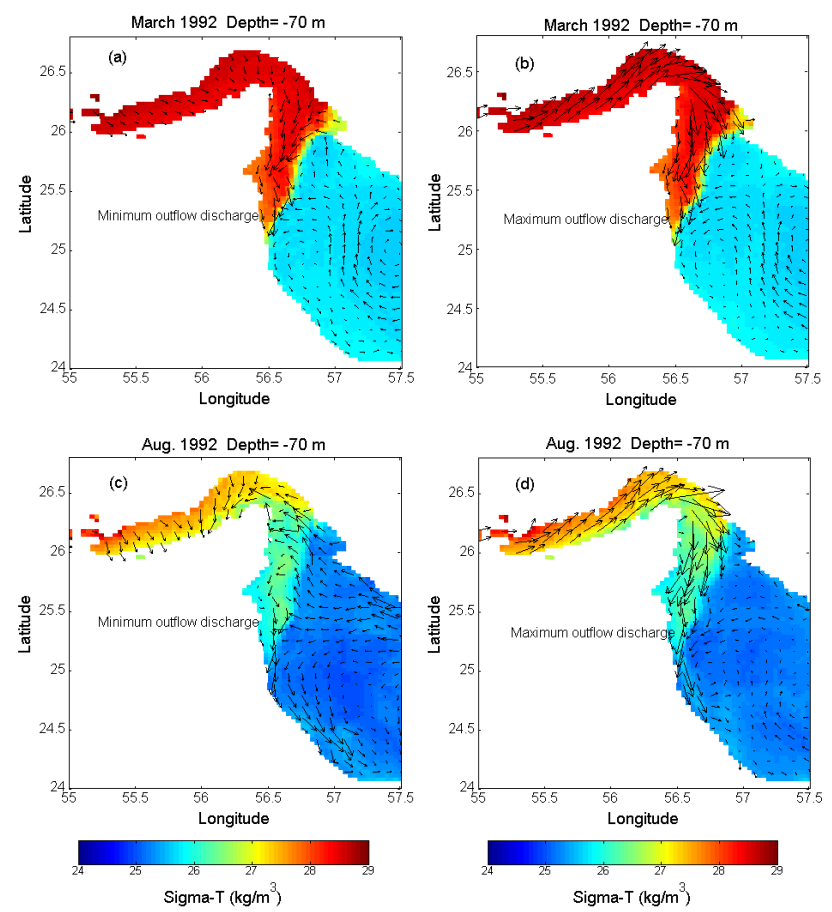

Fig. 22. The snapshots of $\sigma-T$ and velocity fields in the minimum and maximum outflow transports during March and August.

These could be related to stronger stratification during March (winter) that leads to less mixing and hence higher outflow density relative to August (summer) as seen in Fig. 11. As a result the outflow movement persists during March, while weaker stratification in August leads to more tidal mixing and hence to occasional outflow suspension. The snapshots of $\sigma-T$ and velocity fields related to maximum and minimum of outflow transports during March and August are shown in Fig. 22 which also indicates these interactive variations.

\section{Conclusions}

A numerical study of the PG outflow including its impacts on the physical properties of the Oman Sea has been carried out using a three-dimensional model, namely the Princeton Ocean Model that has been used widely for estuarine, coastal waters and open-ocean application modelling. The simulation was performed for the year 1992 since direct CTD measurements are available in the region at two different times (early winter and early summer) from the 1992 ROPME expedition.

The model simulation showed nearly good agreement with measurements. The simulation revealed that the mean salinity of the PG outflow source water is almost constant ( $\sim 39$ psu) during the whole year but its mean temperature shows a strong annual cycle that varies between 19 and 
$27^{\circ} \mathrm{C}$. This leads to the variations in the outflow density of order of $2 \mathrm{~kg} \mathrm{~m}^{-3}$ during the year. The maximum and minimum densities of the outflow occur during late winter (March) and midsummer (August) respectively. The highest density of the outflow source water causes it to penetrate to the deeper depths in the Oman Sea during March.

During summer the outflow has a lower source density, hence it spreads into the shallower depths near the coastal boundaries. During March (winter) the outflow with higher density spreads into the deeper parts and separate from the lateral boundary as it approaches the Ras al Hamra Cape, and the larger width of the outflow, steep topography and tidal oscillations appear to generate the Peddies. The inconsistency between the predicted depth of part of the outflow in winter and the limited observational data are indicated in terms of the effects of the possible limitation of sigma coordinate over steep topography, the resolution of the western boundary data for temperature and salinity, double diffusion, surface strong winter buoyancy loss or the flow being supercritical as it enters the Oman sea. Examining these is required for further study of such behaviour.

As a whole, we find that the seasonal variations of the outflow source water characteristics lead to different outflow pathways in the Oman Sea. The outflow is affected by different mechanisms in the Strait of Hormuz and the Oman Sea such as vertical mixing due to interaction by tide that leads to intermittency in outflow into the Oman Sea. The short time variability of the outflow and other dynamical processes such as barotropic and baroclinic instabilities can lead to the outflow intermittency and as a result eddy generation in the Oman Sea which is not considered in the present work.

We also examined the role of tidal mixing on the initial density of the outflow source water. The results indicated that the mean salinity of the outflow source water could reach to more than $40.2 \mathrm{psu}$ (as opposed to $39.3 \mathrm{psu}$ ) when tide is not included in the simulations (it is not shown here). It shows that tidal mixing has a strong effect on the initial density of the outflow source water at the Strait of Hormuz.

Finally, it is necessary to say that we used the coarse resolution monthly mean climatological data as representative of salinity and temperature of the inflows to the model domain. It is believed that the more accurate prescriptions of $T$ and $S$ from direct measurements at the western boundary, or eliminating the western open boundary by extending the modelling area to the entire Persian Gulf and the Oman Sea, will improve the model simulation results.

\section{Appendix A}

\section{Boundary conditions}

\section{A1 Open boundary conditions (OBCs)}

For the external mode, the normal barotropic velocities at the open boundaries are considered by a type of radiation boundary condition (e.g. Flather, 1976; Korres and Lascaratos, 2003; Mellor, 2003) of the following form:

$H \bar{U} \pm c_{\mathrm{e}} \eta=0$

where $H$ is the water depth at corresponding grid, $\bar{U}$ is the normal barotropic velocity, $c_{\mathrm{e}}$ is the external mode phase speed and is equal to $\sqrt{g H}$ and $\eta$ is the sea surface elevation at corresponding grid.

The amplitudes and phase speeds of the four major tidal constituents (M2, S2, O1 and K1) are prescribed at the open boundaries from the Admiralty Tide Table and assumed as constant along the boundaries. The data are relevant to Kish Island at the western and Konarak port at the eastern boundaries in vicinity of the Iranian coast. However, these lead to less than $10 \%$ errors in prescriptions of each tidal constituent (amplitudes and phases) near the Strait of Hormuz, where the interaction between density front and tidal front occurs, and thus seem to be appropriate for the aim of this study.

For the surface elevation at the boundaries, a zero gradient condition of the following form is adopted:

$\frac{\partial \eta}{\partial n}=0$

For the internal mode, the baroclinic normal velocities at the open boundaries are calculated by adapting the Sommerfeld radiation condition:

$\frac{\partial u_{i}}{\partial t}+c_{\mathrm{i}} \frac{\partial u_{i}}{\partial n}=0$

where, $u_{i}$ is the normal baroclinic velocity, $n$ is a direction perpendicular to the open boundary and $c_{\mathrm{i}}$ is the phase speed of internal mode propagation and is calculated using Orlanski (1976) scheme.

In both barotropic and baroclinic modes, the component of the velocities parallel to the open boundaries are assumed to be zero.

For the temperature and salinity at the open boundaries, whenever the normal velocity is directed outwards from the model domain, an upstream advection scheme of the following form is adopted (e.g. Kantha and Klayson, 2000; Mellor, 2003):

$\frac{\partial T}{\partial t}+u_{i} \frac{\partial T}{\partial n}=0, \quad \frac{\partial S}{\partial t}+u_{i} \frac{\partial S}{\partial n}=0$

In cases of inflow through the open boundaries the temperature and salinity are prescribed from the monthly mean climatological values of temperature and salinity from WOA05 
$\left(0.25^{\circ} \times 0.25^{\circ}\right)$. These data are interpolated and extrapolated at the open (eastern and western) boundaries to represent the thermohaline characteristics of the inflow water into the modeling area.

\section{A2 Surface boundary conditions}

The momentum boundary condition at the surface is set to:

$-K_{\mathrm{M}}(\partial U / \partial z, \partial V / \partial z)_{z=0}=\frac{\left(\tau_{x}, \tau_{y}\right)_{z=0}}{\rho_{\mathrm{w}}}$

where $\left(\tau_{x}, \tau_{y}\right)_{z=0}=\rho_{\mathrm{a}} C_{\mathrm{D}}\left|\boldsymbol{U}_{10}\right|\left(U_{10}, V_{10}\right)$

where $K_{\mathrm{M}}$ is the vertical kinematic eddy viscosity, $\left(\tau_{x}, \tau_{y}\right)$ is the directional wind stress at the sea surface, $\rho_{\mathrm{w}}$ and $\rho_{\mathrm{a}}$ are the density of water and air respectively, $\left|\boldsymbol{U}_{10}\right|$ is the magnitude of the wind speed at $10 \mathrm{~m}$ level above the sea surface and $C_{\mathrm{D}}$ is the wind speed dependent drag coefficient and is calculated according to Geernaert et al. (1986) as follows:

$C_{\mathrm{D}}=10^{-3}\left(0.43+0.097\left|\boldsymbol{U}_{10}\right|\right)$

In the model, the monthly mean values of wind speed components over the domain are taken from ICOADS in 1992 $\left(1^{\circ} \times 1^{\circ}\right.$ resolution) and are interpolated onto the model gird.

The sea surface temperature boundary condition is:

$\left.T\right|_{z=0}=T_{\mathrm{S}}$

where $T_{\mathrm{S}}$ is the SST prescribed from AVHRR data with $0.04^{\circ} \times 0.04^{\circ}$ resolution. The monthly mean values of SST in 1992 are mapped on the model grid after interpolation.

In addition, the monthly mean net shortwave radiation is applied at the sea surface and is taken from NCEP with approximately $1.9^{\circ} \times 1.9^{\circ}$ resolution interpolated onto the model grid points.

The sea surface salinity boundary condition is set to:

$$
-K_{\mathrm{H}}(\partial S / \partial z)_{z=0}=Q_{\mathrm{S}}=-\frac{S_{\mathrm{S}}}{\rho_{\mathrm{W}}}(\stackrel{\circ}{E}-\stackrel{\circ}{P})
$$

where $K_{\mathrm{H}}$ is the vertical eddy diffusivity, $Q_{\mathrm{S}}$ is the salt flux at the surface, $S_{\mathrm{S}}$ is the model surface salinity, $\stackrel{\circ}{E}$ and $\stackrel{\circ}{P}$ are evaporation rate and precipitation rate respectively. In Eq. (A8) the mean monthly precipitation rates in 1992 are taken from NCEP data $\left(\sim 1.9^{\circ} \times 1.9^{\circ}\right)$ and are interpolated onto the model grid points, and the evaporation rates are calculated according to the classical bulk aerodynamic formula (Korres and Lascaratos, 2003) by:

$$
\stackrel{\circ}{E}=0.622 C_{\mathrm{E}}\left|\boldsymbol{U}_{10}\right|\left(e_{\mathrm{SAT}}\left(T_{\mathrm{S}}\right)-R e_{\mathrm{SAT}}\left(T_{\mathrm{A}}\right)\right) \frac{\rho_{\mathrm{A}}}{P_{\mathrm{A}}}
$$

where $C_{\mathrm{E}}$ is the turbulent exchange coefficient and is calculated using a formula given in Kondo (1975). $e_{\text {SAT }}$ is the atmospheric saturation vapor pressure and is computed through a polynomial approximation as a function of temperature (Lowe, 1977), $P_{\mathrm{A}}$ is the atmospheric pressure, $R$ is the relative humidity, $T_{\mathrm{A}}$ is the air temperature in Kelvin at $2 \mathrm{~m}$ above the sea surface, $\rho_{\mathrm{A}}$ is the density of moist air and is computed as a function of air temperature and relative humidity.

Acknowledgements. We would like to thank the ocean modelling department of Princeton University for making the code available online, and the anonymous referees of the OS journal because of their contributions and constructive comments concerning this paper. In addition, we appreciate the OS editorial board for their efforts during review process, especially J. Johnson for English improvement of the paper.

Edited by: J. Johnson

\section{References}

Afanasyev, Ya. D. and Peltier, W. R.: On breaking internal waves over the sill in Knight Inlet, Proc. R. Soc. Lond., 457, 2799 2825, doi:10.1098/rspa.2000.0735, 2001.

Bidokhti, A. A. and Ezam, M.: The structure of the Persian Gulf outflow subjected to density variations, Ocean Sci., 5, 1-12, doi:10.5194/os-5-1-2009, 2009.

Blumberg, A. F. and Mellor, G.L.: A description of a threedimensional coastal ocean circulation model, in: ThreeDimensional Coastal Ocean Models, edited by: Heaps, N., American Geophysical Union, 1-16, 1987.

Brewer, P. G., Fleer, A. P, Kadar, S., Shafer, D. K., and Smith, C. L.: Report A: Chemical oceanographic data from the Persian Gulf and the Gulf of Oman, Rep. WHOI-78-37, 105 pp., 1978.

Bower, A. S., Armi, L., and Ambar, I.: Lagrangian observations of meddy formation during a Mediterranean Undercurrent seeding experiment, J. Phys. Oceanogr., 2545-2575, 1997.

Bower, A. S., Hunt, H. D., and Price, J. F.: Character and dynamics of the Red Sea and Persian Gulf outflow, J. Geophys. Res., 105(C3), 6387-6414, 2000.

D'Asaro, E. A.: Generation of submesoscale vortices: A new mechanism, J. Geophys. Res., 93, 6685-6693, 1988.

Chao, S. Y., Kao, T. W., Al-Hajri, K. R.: A numerical investigation of circulation in the Persian Gulf, J. Geophys. Res., 97(C7), 11219-11236, 1992.

Flather, J.: A tidal model of the northwest European continental shelf, Mem. Soc. R. Sci. Liege, Ser., 6, 10, 141-164, 1976.

García Berdeal, I., Hickey, B. M., and Kawase, M.: Influence of wind stress and ambient flow on a high discharge river plume, J. Geophys. Res., 107, 3130, doi:10.1029/2001JC000932, 2002.

Garvine, R. W.: Penetration of buoyant coastal discharge onto the continental shelf: A numerical model experiment, J. Phys. Oceanogr., 29, 1892-1909, 1999.

Geernaert, G. L., Katsaros, K. B., and Richter, K.: Variation of the drag coefficient and its dependence on sea state, J. Geophys. Res., 91, 7667-7679, 1986.

John, V. C., Cloes, S. L., and Abozed A. L.: Seasonal cycles of temperature, salinity and watermass of the Arabian Gulf, Oceanol Acta, 13, 273-281, 1990.

Johns, W. E., Yao, F., Olson, D. B., Josey, S. A., Grist, J. P., and Smeed, D. A.: Observations of seasonal exchange through the Straits of Hormuz and the inferred freshwater bud- 
gets of the Persian Gulf, J. Geophys. Res., 108(C12), 3391, doi:10.1029/2003JC001881, 2003.

Jungclaus, J. H.: A three dimensional simulation of the formation of anticyclonic lenses (meddies) by the instability of an intermediate depth boundary current, J. Phys. Oceanogr., 29, 1579-1598, 1999.

Jungclaus, J. H. and Mellor, G. L.: A three-dimensional model study of the Mediterranean outflow, J. Marine Syst., 24, 41-66, 2000.

Kantha, L. H. and Clayson, C. A.: Numerical models of oceans and oceanic processes, International Geophysics Series, Vol. 66, Academic Press, pp. 940, 2000.

Kondo, J.: Air-sea bulk transfer coefficients in diabatic conditions, Bound.-Lay. Meteorol., 9, 91-112, 1975.

Korres, G. and Lascaratos, A.: A one-way nested eddy resolving model of the Aegean and Levantine basins: implementation and climatological runs, Ann. Geophys., 21, 205-220, doi:10.5194/angeo-21-205-2003, 2003.

Lowe, P. R.: An approximating polynomial for the computation of saturation vapor pressure, J. Appl. Meteorol., 16, 100-103, 1977.

Matsuyama, M., Kitade, Y., and Senjyu, T.: Vertical structure of current and density front in the Strait of Hormuz, Offshore Environments of the ROPME after the War related Oil-Spill, 23-34, 1998.

Mellor, G. and Yamada, T.: Development of a Turbulence Closure Model for Geophysical Fluid Problems, Rev. Geophy. Space Phys., 20, 4, 851-857, 1982.
Mellor, G. L.: Users guide for a three-dimensional, primitive equation, numerical ocean model, Prog. in Atmos. and Ocean. Sci., Princeton University, 2003.

Mesinger, F. and Arakawa, A.: Numerical methods used in atmospheric models, GARP Publication Series, No. 14, WMO/ICSU Joint Organizing Committee, 64 pp., 1976.

Orlanski, I.: A simple boundary condition for unbounded hyperbolic flows, J. Comp. Phys., 21, 251-269, 1976.

Pous, S. P., Carton, X., and Lazure, P.: Hydrology and circulation in the Strait of Hormuz and the Gulf of Oman result from the GOGP99 Experiment: 2. Gulf of Oman, J. Geophys. Res., 109, C12038, doi:10.1029/2003JC002146, 2004.

Reynolds, R. M.: Overview of physical oceanographic measurements taken during the Mt. Mitchell Cruise to the ROPME Sea Area, Mar. Pollut. Bull., 27, 35-59, 1993.

Senjyu, T., Ishimaru, T., Matsuyama, M., and Koike, Y.: High salinity lens from the Strait of Hormuz, Offshore Environments of the ROPME after the War related Oil-Spill, 35-48, 1998.

Spall, M. A.: Buoyancy-Forced Down-welling in Boundary Currents, J. Phys. Oceanogr., 38, 2704-2721, 2008.

Stern, M. E.: Geostrophic fronts, bores, breaking and blocking waves, J. Fluid Mech., 99, 687-704, 1980.

Swift, S. A. and Bower, A. S.: Formation and circulation of dense water in the Persian Gulf, J. Geophys. Res., 108(C1), 3004, doi:10.1029/2002JC001360, 2003. 